\title{
Pengaruh Gaya Kepemimpinan, Motivasi, Dan Lingkungan Kerja Terhadap Kepuasaan Kerja Karyawan PT Niagamas Lestari Gemilang Di Jakarta Barat
}

\author{
Michael dan Muhammad Tony Nawawi \\ Program Studi Manajemen Fakultas Ekonomi \& Bisnis, Universitas Tarumanagara \\ Email: michaeltarsisius1@gmail.com
}

\begin{abstract}
The purpose of this study was to determine the effect leadership style, motivation, and work environment for job satisfaction. The sampling method in this study use probability sampling. Sample in this research is 100 employee on PT. Niagamas Lestari Gemilang in Jakarta. Data collection technique is done by deviding quisioner. Data analysis technique used SmartPLS 3.0. The result of this study is leadership style, and work environment have significant positive effect on job satisfaction, and motivation have insignificant positive effect on job satisfaction.
\end{abstract}

Keyword: Leadership style, Motivation,Work Evironment, Job Satisfaction.

Abstrak: Tujuan penelitian ini adalah untuk menentukan pengaruh gaya kepemimpinan, motivasi, dan lingkungan kerja terhadap kepuasaan kerja. Teknik pengambilan sampel dalam penelitian ini adalah probabilitas sampel. Sampel dalam penelitian ini adalah 100 karyawan PT. Niagamas Lesatari Gemilang yang berada di Jakarta. Teknik pengumpulan data dilakukan dengan penyebaran kuisioner. Teknik analisis data menggunakan SmartPLS 3.0. hasil dalam penelitian ini adalah gaya kepemimpinan, dan lingkungan kerja mempunyai pengaruh yang signifikan terhadap kepuasaan kerja, dan motivasi mempunyai pengaruh postif yang tidak signifikan terhadap kepuasan kerja.

Kata Kunci: Gaya Kepemimpinan, Motivasi, Lingkungan Kerja, Kepuasaan Kerja.

\section{LATAR BELAKANG}

Sumber daya manusia merupakan salah satu faktor terpenting yang mempengaruhi keberhasilan suatu perusahaan. Di era global ini, kebutuhan akan sumber daya manusia yang berkualitas untuk sebuah perusahaan adalah sangat penting dimiliki oleh suatu perusahaan. Pemilihan sumber daya manusia yang berkualitas harus diperhatikan guna menunjang keberhasilan produktivitas perusahaan Dalam memenuhi kebutuhan sumber daya manusia yang berkualiatas, seorang manejer perusahaan harus mampu menjaga hubungan baik dengan karyawan serta memerhatikan perilaku karyawan, fasilitas kerja, dan kompensasi agar terciptanya kepuasaan karyawan.

(Nawawi, 2015) Mengatakan Kepuasan Kerja merupakan salah satu faktor sangat penting yang mempengaruhi kepuasan hidup karena hampir sebagian besar waktu manusia 
dihabiskan di tempat kerja. Ketika karyawan merasa puas dan nyaman dengan iklim atau keadaan pekerjaan mereka, karyawan akan memberikan effort kerja yang lebih pada pekerjaannya yang akhirnya dapat mendatangkan peluang pada keberhasilan perusahaan, dengan demikian produktivitas dan hasil kerja karyawan akan meningkat secara optimal sehingga ada peluang untuk suatu keberhasilan perusahaan.

Dalam mewujudkan kepuasaan kerja pada karyawan Gaya Kepemimpinan pun juga memegang peranan penting. Yukl (2015:9) mengemukakan bahwa kepemimpinan adalah proses seseorang dalam mempengaruhi orang lain atau kelompok untuk memahami dan setuju dengan apa yang perlu atau harus dilakukan dan bagaimana tugas tersebut sepantasnya dilaksanakan secara efektif, serta proses untuk memfasilitasi upaya individu dan kolektif untuk mencapai tujuan bersama.

Sejalan dengan gaya kempemimpinan di atas, motivasi juga dibutuhkan dalam menentukan tingkat kepuasan karyawaan. Hasibuan $(2010,141)$, motivasi semakin penting karena atasan membagikan pekerjaan pada bawahannya untuk dikerjakan dengan baik menuju tujuan yang diinginkan.

Hal lain yang juga penting dalam meningkatkan kepuasan karyawan selain dari gaya kepemimpinan dan motivasi di atas adalah lingkungan kerja. Sedarmayanti (2011:1) lingkungan kerja adalah keseluruhan peralatan, perlengkapan, metode bekerja, lingkungan sekitar dimana seseorang atau kelompok bekerja, serta pengaturan kerja baik perseorangan atau sebagai kelompok .

Dari pemaparan di atas, peneliti mengambil lokasi penelitian di PT Niagamas Lestari Gemilang, yang beralamat kan pada Jalan Mangga Besar, Taman Sari, Jakarta Barat. PT Niagamas Lestari Gemilang tersebut bergerak pada bidang Mesin, perkakas, \& alat industri. Adapun masalah yang dihadapi lingkungan kerja PT Niagamas Lestari Gemilang adalah menurunnya produktivitas karyawan, dan keterlambatan target penjualan yang ingin dicapai, yang terindikasi karena banyaknya karyawan kurang puas baik karena gaji yang diberikan relatif rendah atau gaya kepemimpinan yang kurang tepat sehingga karyawan tidak dapat memaksimalkan perannya. Oleh karena itu, penelitian ini diberi judul "Pengaruh Gaya Kepemimpinan, Motivasi, Lingkungan Kerja Terhadap Kepuasan Karyawan pada PT Niagamas Lestari Gemilang.

Perumusan masalah, 1)Apakah gaya kepemimpinan mempunyai pengaruh terhadap kepuasaan kerja karyawan PT Niagamas Lestari Gemilang?. 2)Apakah lingkungan kerja mempunyai pengaruh terhadap kepuasaan karyawan?. 3)Apakah motivasi kerja mempunyai pengaruh terhadap kepuasaan karyawan?

\section{KAJIAN TEORI}

Thoha (2013:49) Gaya kepemimpinan merupakan norma perilaku yang akan digunakan oleh seseorang pada saat orang tersebut akan mencoba mempengaruhi perilaku orang lain seperti yang ia lihat. 
Menurut Samsudin (2010: 281) mengemukakan bahwa motivasi adalah proses mempengaruhi atau mendorong dari luar terhadap seseorang atau kelompok kerja agar mereka mau melaksanakan sesuatu yang telah ditetapkan.

Sedarmayanti (2011:1) lingkungan kerja adalah keseluruhan peralatan, perlengkapan, metode bekerja, lingkungan sekitar dimana seseorang atau kelompok bekerja, serta pengaturan kerja baik perseorangan atau sebagai kelompok .

Dadang (2013:15) adalah suatu keadaan emosional yang menyenangkan atau tidak menyenangkan terhadap pekerjaannya, kepuasan kerja dapat mencerminkan perasaan seseorang karyawan terhadap pekerjaannya.

Model Penelitian ini digambarkan sebagai berikut:

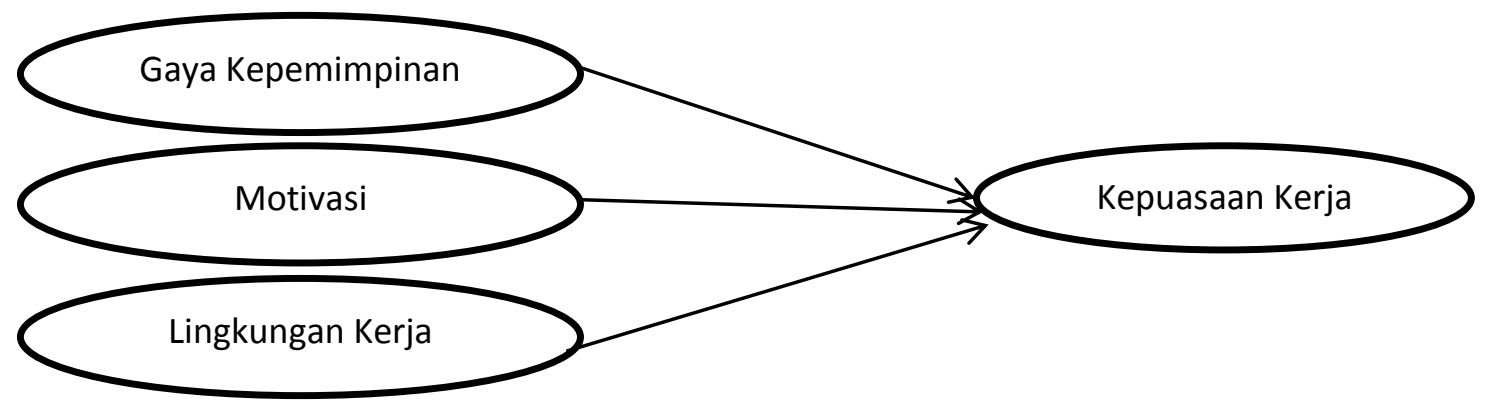

Gambar 1. Model Penelitian

Dengan Hipotesis sebagai berikut:

H1: Terdapat pengaruh antara Kompensasi dengan Kepuasaan Kerja .

H2: Terdapat pengaruh atara Motivasi dengan Kepuasaan Kerja.

H3: Terdapat pengaruh antara Lingkungan Kerja dengan Kepuasaan Kerja.

\section{METODOLOGI}

Data penelitian ini didapatkan dengan menyebarkan kuisioner kepada sebagian besar dari karyawan PT Niagamas Lestari Gemilang di daerah Jakarta. Penelitian ini berfokus pada kepuasaan kerja. Pemilihan sampel yang dilakukan adalah probability sampel.

Variabel oprasional dalam penelitian ini adalah Gaya Kepemimpinan, Motivasi, dan Lingkungan Kerja yang merupakan variabel independen sedangkan Kepuasan Kerja sebagai variabel dependen. Gaya Kepemimpinan diukur dengan indikator dari Kartono(2013:34), Motivasi diukur dengan indikator dari Kadarisman(2012:306), Lingkungan Kerja diukur dengan indikator dari Sedarmayati(2011:26), dan Kepuasaan 
Kerja diukur dari indikator Robbin(2010:110).

Penelitian ini Menggunakan Skala Linkert dengan menjadikan setiap indikator sebagai titik tolak ukur dan melakukan penyebaran kuisioner secara manual dengan menggunakan kuisioner.

\section{HASIL ANALISIS DATA}

Berdasarkan data yang yang telah diperoleh sebanyak 100(100\%) responden, maka dapat diketahui karakteristik responden berdasarkan jenis kelamin laki laki sebanyak 55(55\%) responden, dan Perempuan sebanyak 45(45\%). Untuk karakteristi responden berdasarkan usia responden dengan usia dibawah 30 tahun sebanyak 64(64\%) responden, untuk usia diantara 30 tahun hingga 50 tahun sebanyak 30(30\%) responden, dan untuk diatas 50 tahun sebanyak 6(6\%). Karakteristik responden berdasarkan lama bekerja, responden dibawah 1 tahun berjumlah 52(52\%), responden diantara 1 hingga 5 tahun berjumlah 30(30\%), responden diatas 5 tahun berjumlah 18(18\%) responden.

Data yang telah dikumpulkan akan diuji didalam aplikasi SmartPLS 3.0 yang akan melewati uji convergen Validity dan Discriminat Validity. Dalam Discriminant Validt dapat dilakukan dengan cara melakukan perbandingan antar nilai square root Average Varience Extracted(AVE) setiap konstruk dengan korelasi konstruk lain dalam model disarankan AVE harus lebih besar dari 0,5.

Dalam Convergent Validty, minimalnya semua secara statistik harus lebih dari 0,5, tetapinya idealnya lebih 0,7.(Malhotra,2010:275).I

Tabel 1. Hasil Nilai Avarage Varience Extracted

\begin{tabular}{|c|c|}
\hline Variabel & AVE \\
\hline Gaya Kepemimpinan & 0.671 \\
\hline Motivasi & 0.522 \\
\hline Lingkungan Kerja & 0.546 \\
\hline Kepuasaan Kerja & 0.632 \\
\hline
\end{tabular}

Sumber :SmartPLS 3.0

Berdasarkan tabel 1, dapat disimpulkan bahwa variabel Gaya Kepemimpunan, Motivasi, Lingkungan Kerja, Kepuasaan Kerja dinyatakan valid karena telah melewati standar Average Variance Extracted yaitu $>0.5$. 
Gambar 2. Ouput Smartpls Loading Factor

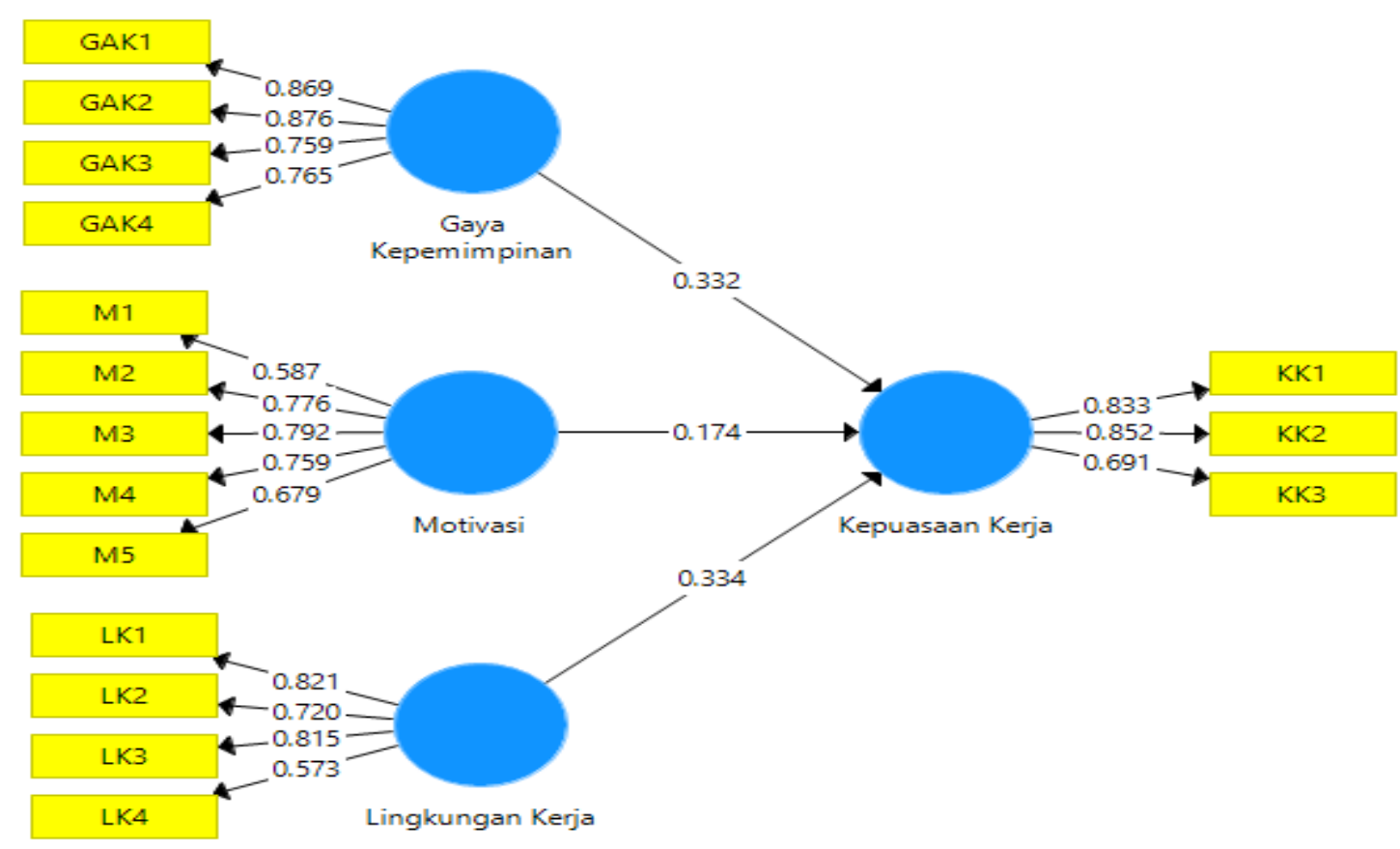

Sumber: SmartPLS 3.0

Dapat dilihat dari gambar 2 bahwa nilai faktor loading berada pada tingkatan nilai yang cukup atau pada nilai yang masih diijinkan yaitu $>0,5$. Sedangkan nilai terkecil pada loading faktor adalah 0,573 yang berada pada indikator lingkungan kerja(LK4). maka dapat disimpulkan semua indikator pada penelitian ini adalah valid.

Tabel 2. Cronbatch's Alpha

\begin{tabular}{|c|c|}
\hline Variabel & Cronbatch's Alpha \\
\hline Gaya Kepemimpinan & 0.836 \\
\hline Motivasi & 0.770 \\
\hline Lingkungan Kerja & 0.713 \\
\hline Kepuasaan Kerja & 0705 \\
\hline
\end{tabular}

Sumber: SmartPLS 3.0

Menurut Imam Ghozali (2012:47) uji reliabilitas adalah alat untuk mengukur suatu kuesioner yang merupakan indikator dari variabel atau konstruk. Uji reabilitas dilakukan untuk mengetahui suatu instrument yang telah dirancang dalam bentuk kuisoner dapat diandalkan atau tidak. Maka dapat disimpulkan pada table 2 bahwa semua nilai Cronbach's Alpha pada setiap variabel adalah diatas 0.6, maka variabel tersebut dapat dinyatakan reliabel.

Setelah pengujian outer model(Validitas dan Reabilitas) peneliti melakukan pengujian inner model(model struktural) untuk mengetahui kotribusi dari variabel 
independen $(X)$ terhadap variabel dependen $(Y)$. pengujian inner model meliputi koefisien determinasi $\left(\mathrm{R}^{2}\right)$ dan path coefficient.

Tabel 3. Output Smartpls $R$ square

\begin{tabular}{|c|c|}
\hline & $\boldsymbol{R}$ Square \\
\hline Kepuasaan Kerja & 0,527 \\
\hline
\end{tabular}

Sumber: SmartPLS 3.0

Berdasarkan tabel 3 dapat dilihat besar koefisien determinasi $\left(\mathrm{R}^{2}\right)$ adalah sebesar 0,527 yang memiliki arti 52,7\% variabel dependen kepuasaan kerja dapat dijelaskan oleh variabel independen gaya kepemimpinan, motivasi, dan lingkungan kerja. Sisanya sebesar $46,3 \%$ dapat dijelaskan oleh variabel lain.

Tabel 4. Path Coefficient

\begin{tabular}{|l|l|l|l|l|}
\hline & $\begin{array}{c}\text { Original } \\
\text { Sampel }\end{array}$ & $\begin{array}{c}\text { Sampel } \\
\text { mean }\end{array}$ & $\begin{array}{c}\text { Standart } \\
\text { Deviation }\end{array}$ & T statistict \\
\hline Gaya Kepemimpinan & 0.332 & 0.324 & 0.146 & 2.285 \\
\hline Lingkungan kerja & 0.334 & 0.339 & 0.081 & 4.131 \\
\hline Motivasi & 0.174 & 0.187 & 0.108 & 1.618 \\
\hline
\end{tabular}

Sumber: SmartPLS 3.0

\section{DISKUSI}

Dalam table 4 dapat diketahui bahwa variabel Gaya Kepemimpinan dan Lingkungan Kerja mempunyai pengaruh yang signifikan terhadap Kepuasaan Kerja,hal ini dapat dilihat dari nilai t Gaya kepemimpinan, dan Lingkungan kerja lebih besar dari 1,96 Hasil ini juga didukung oleh peneliti terdahulu (Saputra \& Adnyani, 2017). (Aruan \& Fakhri, 2015). Sedangkan variabel motivasi tidak mempunyai pengaruh yang signifikan terhadap kepuasaan kerja hal ini dikarenakan nilai t motivasi tidak melebihi nilai 1,96. Hasil ini didukung oleh peneliti terdahulu (Ariani \& Assarofa, 2018).

\section{PENUTUP}

Berdasarkan hasil penelitian dari pengujian data dalam penlitian ini menunjukan bahwa Gaya Kepemimpinsn, dan Lingkungan Kerja Mempunyai pengaruh postif dan signifikan terhadap kepuasaan kerja PT Niagamas Lestari Gemilang, sedangkan Motivasi mempunyai pengaruh positif tapi tidak signifikan terhadap kepuasaan kerja Niagamas Lestari Gemilang.

\section{Saran}

1. Bagi perusahaan, Dalam hal ini, peneliti menyarankan PT. Niagamas Lestaris Gemilang memberikan kesempatan kepada karyawan berpatisipasi dalam proses pengambilan keputusan agar para karyawan dapat lebih berkembang dalam perusahaan, hal ini juga akan meningkatkan tingkat kepuasaan dalam perusahaan karena karyawan akan lebih senang bekerja di perusahaan yang dapat membuat dirinya lebih berkembang.

2. Peningkatan kepuasaan karyawaan dapat dilakukan dengan memperhatikan kebutuhan karyawan .karena bila kebutuhan karyawaan tercukupi karyawaan tersebut akan lebih 
senang dan lebih nyaman dalam bekerja diperusahaan tersebut. Mereka akan merasa lebih dihargai oleh perusahaan tempat mereka bekerja.

3. Atasan disarankan untuk dapat menjaga dan mempererat hubungan para karyawannya, bila berlangsung baik maka karyawan pun lebih bahagia dalam bekerja , tidak merasa terbebani bekerja disekeliling rekan rekannya dan dapat memberikan hasil kerja yang lebi maksimal

4. Untuk peneliti di masa mendatang disarankan untuk menambah atau menggunakan variabel lain dalam meneliti kepuasaan kerja. penambahan variabel lain seperti fasilitas kerja, kompensasi, dan perilaku karyawan.

\section{DAFTAR PUSTAKA}

Ahmad, Chandra \& Dadang Hermawan.(2013). E-Business \& E-Commerce. Andi, Yogyakarta.

Ariani, H. M., \& Assarofa, A. (2018). Pengaruh Motivasi , Disiplin , Dan Lingkungan Kerja Pada PT Palma Plantasindo Di Desa Sunge Batu Kecamatan Pasir Belengkong Kabupaten Pasar. Conference on Management and Behavioral Studies, (2541-3406), $68-77$.

Aruan, Q. S., \& Fakhri, M. (2015). Kerja Karyawan Lapangan Departemen Grasberg Power Distribution Pt . Freeport Indonesia. Modus, 27(2), 141-162

Ghozali, Imam.(2012). Aplikasi Analisisi Multivariate dengan Program IBM SPSS. Universitas Diponegoro, Yogyakarta.

Hasibuan.(2010).Manajemen Sumber Daya Manusia. Jakarta: Bumi Aksara.

Kadarisman.(2012). Manajemen Pengembangan Sumber Daya Manusia, PT Rajawali , Jakarta.

Kartono, Kartini.(2013). Kepemimpinan dalam Manajemen: Apakah Kepemimpinan abnormal itu?,edisi 1,PT Rajawali, Jakarta.

Naresh, K. Malhotra.(2010). Marketing Research: An Applied Orientation Sixth edition Pearson Education.

Nawawi, M. T. (2015). Pengaruh Kepuasan Kerja, Dan Motivasi Kerja Terhadap Kinerja Karyawan/ti Dengan Komitmen Organisasional Sebagai Variabel Intervening (Studi Karyawan Outsourcing PT. J Yang Ditempatkan Di Kampus II Untar Jakarta), 3(13), 129-147.

Robbins, Stephen P. \& Coulte, Mary.(2010). Manajemen. Edisi 10. Erlangga, Jakarta.

Samsudin, Sadili.(2010). Manajemen Sumber Daya Manusia. Pustaka Setia, Bandung.

Saputra, I. G. A. E., \& Adnyani, I. G. A. D. (2017). TERHADAP KEPUASAN KERJA KARYAWAN Fakultas Ekonomi dan BisnisUniversitas Udayana ( Unud ), Bali , Indonesia ABSTRAK Sumber Daya Manusia mempengaruhi tercapainya suatu tujuan perusahaan. Mengelola Sumber Daya Manusia dalam suatu organisasi bukan hal yang m. E-Jurnal Manajemen Unud, 6(12), 6592-6619.

Sedarmayanti,(2011).Manajemen Sumber Daya: Reformasi Birorkrasi dan Manajemen Pegawai Negeri Sipil(cetakan ke 5).PT refika Aditama, Bandung.

Thoha,Mifta.(2013).Kepemimpinan dalam Manajemen,edisi1,PT RajaGrafindo, Jakarta.

Yukl, Gary. (2015), Leadership in Organizations, Seventh Edition, PT. Indeks, Jakarta. 